\title{
Breve análise da estratégia da União Europeia (UE) para a eficiência energética do ambiente construído
}

\author{
Brief analysis of the European Union (EU) strategy for the \\ energy efficiency of the built environment
}

\section{Fernando Pacheco Torgal}

\section{Resumo}

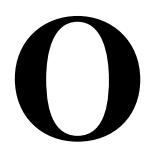

aquecimento global é um dos mais graves problemas com que se depara o Planeta Terra. Este problema se origina do aumento da concentração de gases de efeito estufa $\left(\mathrm{CO}_{2}\right)$ na atmosfera. Esses gases provêm, na sua maioria, da queima de combustíveis fósseis para produção de energia. $\mathrm{Na}$ Europa as emissões relacionadas com a produção de energia representam a maior parte das emissões totais. Portanto, a fim de lidar com o problema do aquecimento global, os países da União Européia (UE) decidiram que em 2020 seu nível de emissões conjunto será 20\% inferior ao de 1990 e ainda que em 2050 essa redução deverá situar-se entre 80\% e 95\% abaixo do nível de emissões de 1990. Além disso, a UE se comprometeu a aumentar em $20 \%$ o consumo de energia oriunda de fontes renováveis. $\mathrm{O}$ aumento da eficiência energética em edifícios novos e existentes é fundamental para a transformação do sistema energético da UE. O presente artigo analisa sucintamente a estratégia da UE para a eficiência energética no ambiente construído.

Palavras-chave: Emissões de $\mathrm{CO}_{2}$. Alterações climáticas. Eficiência energética. Edifícios de energia quase zero. Toxicidade. Energia incorporada.

Fernando Pacheco Torgal Universidade do Minho Guimarães - Portugal

Recebido em 12/03/13 Aceito em 09/05/13

\section{Abstract}

Climate change is one of the most serious environmental problems that the planet faces today. This problem is due to an increasing concentration of of greenhouse gases $\left(\mathrm{CO}_{2}\right)$ in the atmosphere. Most of those gases originate from the burning of fossil fuels for energy production. Energy related emissions account for the largest share of the EU's total greenhouse gas emissions. Therefore, in order to tackle climate change, the EU has agreed that, by 2020, greenhouse gas emissions must have dropped to a level $20 \%$ lower than the 1990 emissions level, and also that by 2050 those levels must be between $80 \%$ and $95 \%$ lower than the 1990 level.

Moreover the EU committed to a $20 \%$ increase in the consumption of energy from renewable sources. Increasing the energy efficiency of new and already existing buildings is crucial for the transformation of the EU's energy system. This paper makes a brief analysis of the EU's energy efficiency strategy for buildings.

Keywords: $\mathrm{CO}_{2}$ emissions. Climate change. Energy efficiency. Nearly zero-energy buildings. Toxicity. Embodied energy. 


\section{Introdução}

No início do século XVIII, o nível de concentração de $\mathrm{CO}_{2}$ na atmosfera era de $280 \mathrm{ppm}$, sendo atualmente de $450 \mathrm{ppm}$ (Figura 1). Na figura referida pode constatar-se que nos últimos $650 \mathrm{mil}$ anos a concentração de $\mathrm{CO}_{2}$ nunca tinha excedido 300 ppm (VIJAYAVENKATARAMAN; INIYAN; GOIC, 2012). A manter-se o nível de emissões atual, o que não é provável, atendendo ao crescimento econômico dos países menos desenvolvidos, como a China ou a Índia, com os consequentes aumentos de taxas de emissões, isso levará muito provavelmente a uma subida dramática do nível de concentração de $\mathrm{CO}_{2}$ para $731 \mathrm{ppm}$ no ano 2130. Por sua vez, este fato implicará um aquecimento global de $3,7^{\circ} \mathrm{C}$ acima dos níveis pré-industriais (VALERO; AGUDELO; VALERO, 2011).

O aquecimento global conduzirá a uma subida do nível do mar provocada pela dilatação térmica da água. Quando essa subida atingir $0,40 \mathrm{~m}$, irá submergir $11 \%$ da superfície de Bangladesh e, em consequência, tal fato irá provocar entre 7 e 10 milhões de desabrigados (INTERGOVERNMENTAL..., 2007). Nota-se que não se contabiliza nessa subida do nível do mar a subida do nível do mar provocada pelo degelo das calotes polares, cujos impactos ainda não estão quantificados com exatidão e podem ser muito substanciais, significando, no mínimo, uma subida de $7 \mathrm{~m}$. Outra consequência do aquecimento global é a ocorrência de fenômenos atmosféricos cada vez mais extremos. $\mathrm{O}$ aquecimento global pode também provocar o degelo do permafrost (solo permanentemente gelado), onde estão retidos aproximadamente $1 \times 10^{6}$ milhões de toneladas $\left(1.000 \mathrm{Gt}\right.$ de $\left.\mathrm{CO}_{2}\right)$ (PACHECO-TORGAL; JALALI, 2011). Esse valor astronômico é equivalente ao total das emissões mundiais atuais durante 30 anos. O aquecimento global pode também contribuir para o colapso da economia mundial. De acordo com Stern e Treasury (2007), o custo das ações conducentes à limitação das emissões de gases responsáveis pelo efeito estufa poderá ascender a aproximadamente $1 \%$ do PIB mundial. Contudo, caso esse objetivo não seja atingido, as consequências ambientais dessas emissões poderão representar um valor de quase
$20 \%$ do PIB mundial. O aumento da concentração de $\mathrm{CO}_{2}$ conduzirá ainda à acidificação da água do mar (HOFMANN; SCHELLNHUBER, 2010; HARROULD-KOLIEB; HERR, 2012). Este fato terá consequências negativas nas formações coralíferas que albergam habitats de elevado valor econômico. É importante recordar que os recifes de coral são habitats cujos recursos de pesca alimentam mais de 1.000 milhões de pessoas e que possuem um valor econômico estimado em 20.000 milhões de euros (BOURNE, 2008; ANTHONY et al., 2008). Nesse contexto, é pertinente referir que globalmente os serviços fornecidos a título gratuito pela natureza foram contabilizados em aproximadamente 33 bilhões $\left(10^{12}\right)$ de dólares/ano há uma década (CONSTANZA et al., 1997). Para ser ter uma ideia do que representa esse valor, é necessário ter presente que, na mesma altura, o PIB em âmbito mundial era de 18 bilhões $\left(10^{12}\right)$ de dólares/ano, o que representa aproximadamente a metade do valor dos serviços e produtos fornecidos pela natureza (CONSTANZA et al., 1997). Isso dá uma pequena ideia do valor daquilo que poderá estar em causa por via da destrutiva ação humana. E mesmo que por remota hipótese todas as emissões de carbono cessassem subitamente, a quantidade já existente na atmosfera iria lá permanecer durante o próximo século. A maioria das emissões de gases com efeito estufa provém da queima de combustíveis fósseis para produção de energia. As centrais termoelétricas a carvão são responsáveis por $20 \%$ das emissões de $\mathrm{CO}_{2} \mathrm{em}$ nível mundial (Figura 2).

No ano 2009 a China tornou-se o maior consumidor de energia em âmbito mundial (INTERNATIONAL..., 2010), país onde as centrais termoelétricas a carvão são responsáveis por $80 \%$ da produção de eletricidade (SHEALY; DORIAN, 2009). Ainda assim é importante reconhecer que, muito embora a China seja responsável pela emissão de um valor total de 9.700 milhões de toneladas de $\mathrm{CO}_{2}$, é responsável pela emissão de apenas 7,2 t de $\mathrm{CO}_{2}$ per capita, enquanto, por exemplo, o Canadá, os EUA e a Austrália são responsáveis por emissões per capita, respectivamente de $16,2,17,3$ e 19 t (JOINT..., 2012). 
Figura 1 - Concentração de $\mathrm{CO}_{2}$ (ppm) com o passar dos anos

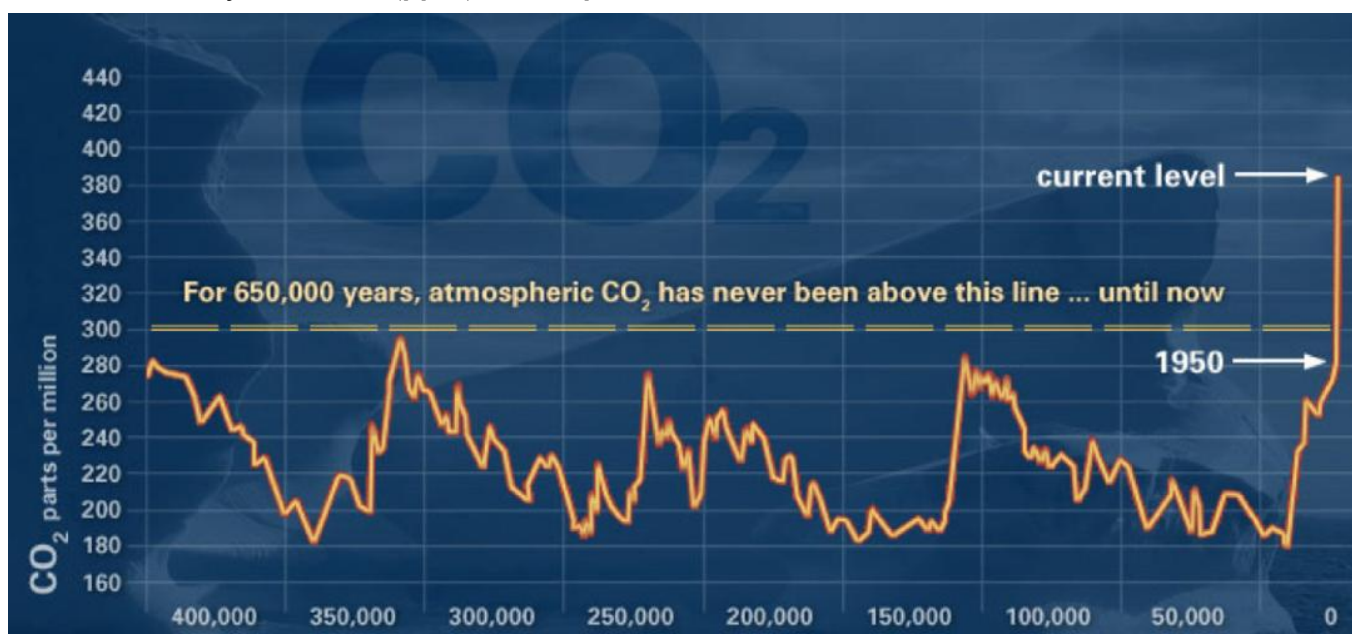

Fonte: Vijayavenkataraman e Iniyan (2012).

Figura 2 - Central termoelétrica a carvão em Hazelwood, Austrália

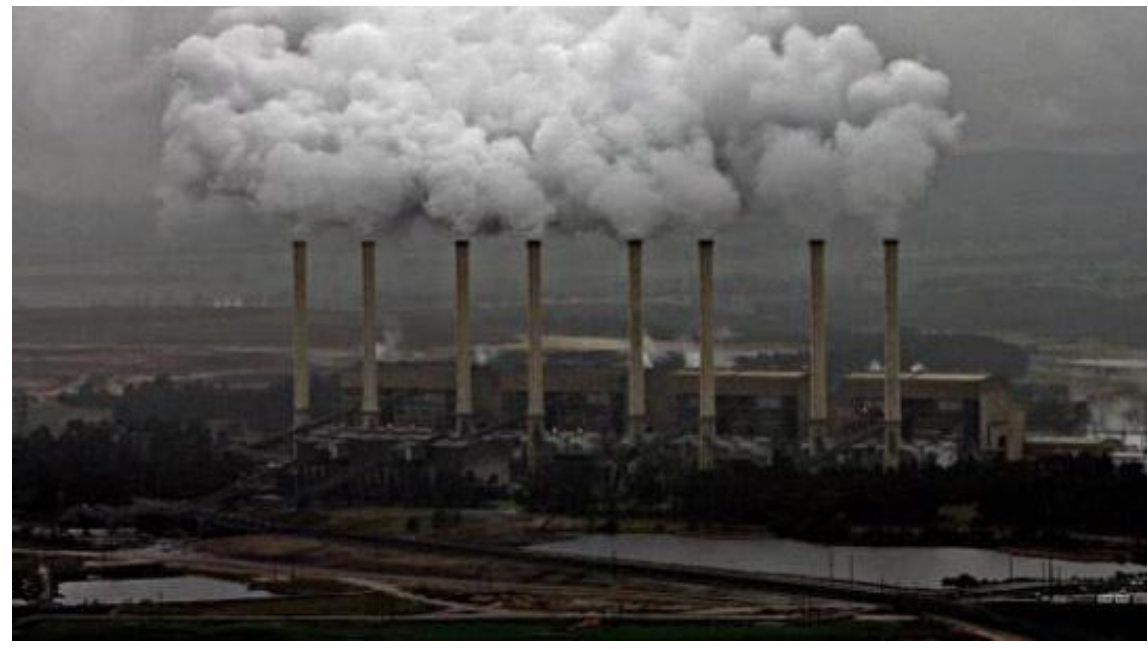

Os países participantes na Cimeira de Copenhagen em 2009 reconheceram a evidência de que "o aumento da temperatura global não deveria exceder $2{ }^{\circ} \mathrm{C}$ ", isso apesar de um número cada vez maior de investigadores ser da opinião que esse valor é muito permissivo. Contudo, os mesmos países não conseguiram chegar a acordo quanto à definição de metas vinculativas e significativas de redução de emissões de carbono (DIMITROV, 2010; NEW et al., 2011). Em vez disso, diferentes países decidiram adotar diferentes metas individuais. Os Estados Unidos aceitaram reduzir em $17 \%$ suas emissões totais de $\mathrm{CO}_{2}$ até 2010, mas relativamente ao ano de 2005 (UNITED..., 2009). Já a China e a Índia não aceitaram uma redução de suas emissões totais, mas, antes, uma redução da intensidade de carbono (carbono/unidade de PIB) até ao ano 2020 , entre $40 \%$ e $45 \%$ para a China, e entre $20 \%$ e $25 \%$ para a Índia (UNITED..., 2009). Goldenberg e Prado (2010) analisaram as referidas metas e referem que elas se limitam a seguir o padrão "business as usual" do período 1990-2007. O que essas metas defendem é manifestamente insuficiente para conseguirem-se reduções significativas até 2020. Essa análise é partilhada por outros autores (PETERSON; SCHLEICH; DUSCHA, 2011). Para tentar contrariar esse estado de coisas, o World Business Council for Sustainable Development estima que até 2050 seja necessário que a eficiência na utilização de recursos tenha de aumentar entre $400 \%$ e $1.000 \%$ (EUROPEAN..., 2011a). De acordo com o World Energy Outlook 2012, a eficiência energética é a área com maior potencial para obterem-se reduções nas emissões de gases com efeito estufa (INTERNATIONAL..., 2012). Apesar disso, os investimentos em projetos ligados à eficiência energética em nível mundial continuam a ser escassos. Um relatório recente (RYAN; SELMET AASRUD, 2012) refere que a eficiência energética 
representa apenas uma parte ínfima dos mais de quase 400 bilhões de dólares que todos os anos são alocados a projetos relacionados com as alterações climáticas. Atualmente o mercado mundial sobre eficiência energética em edifícios representa 68 bilhões de dólares, sendo previsível que atinja 100 bilhões de dólares em 2017 (PIKE, 2011).

\section{Estratégia da UE para a eficiência energética do ambiente construído}

A Europa apresenta o maior valor de importações de recursos per capita e tem uma economia que se assenta fortemente em recursos não renováveis e também no consumo de energia $(40 \%$ só no setor habitacional (LECHTENBOHMER; SCHURING, 2011). Este, por sua vez, é responsável por $80 \%$ das emissões de gases com efeito estufa (COM, 2010). No âmbito de sua estratégia de crescimento inteligente, sustentado e inclusivo, a UE desenvolveu sete iniciativas emblemáticas. Uma delas, designada Resource-efficient Europe (EUROPEAN..., 2011), salienta a importância do aumento da eficiência dos recursos como um fator fundamental no sentido de multiplicar as oportunidades econômicas, aumentar a produtividade, baixar custos e aumentar a competitividade. A estratégia da UE para combater as alterações climáticas passa por uma redução de suas emissões totais até 2020 em $20 \%$ relativamente ao ano de 1990 e ainda por um aumento em $20 \%$ da percentagem de energia proveniente de fontes renováveis (EUROPEAN..., 2008). Entre 2010 e 2020, serão necessários investimentos na área da energia de aproximadamente 1 trilhão de euros, seja para aumentar o nível da diversificação existente, seja para a substituição de equipamentos, e também para providenciar novos requisitos de consumo energético (EUROPEAN..., 2010a). De acordo com o relatório Energy Road Map 2050 (EUROPEAN..., 2011a), o aumento da eficiência energética em edifícios novos e existentes é fundamental para a transformação do sistema energético da UE. Importa ter presente que, das várias áreas relacionadas com $\mathrm{o}$ ambiente construído, tanto a área da eficiência energética como a área das energias renováveis serão as únicas a merecer financiamento no futuro quadro comunitário HORIZON 2020 (EUROPEAN..., 2011b). Também se espera que a área da eficiência energética possa contribuir para a criação de empregos (EUROPEAN..., 2010a). Alguns autores, como Lund e Hvelplund (2012), mostraram recentemente que investimentos em redes de distribuição de aquecimento urbano district heating e de aquecimento individual na Dinamarca permitirão criar entre 7.000 e 8.000 empregos. Apesar disso e como reconhece a própria UE (EUROPEAN..., 2010a), "a qualidade dos planos de acção para a eficiência energética desenvolvidos por cada estado membro desde 2008 é decepcionante, deixando um elevado potencial por explorar". Isso significa que, como reconhece Clements-Croome (2011), são necessárias novas tecnologias e novos processos para tentar resolver esse problema, como, por exemplo, a nova diretiva sobre o desempenho energético dos edifícios.

\section{Diretiva sobre o desempenho energético dos edifícios (European Performance Building Directive - EPBD)}

A Diretiva 2002/91/CE (EPBD) (EUROPEAN..., 2003), relativa ao desempenho energético dos edifícios, foi revista recentemente (2010/31/EU) (EUROPEAN..., 2010a) e aprovada em 19 de maio de 2010 pelo Parlamento e pelo Conselho Europeu. Um dos novos conceitos incluídos na nova EPBD é o conceito relativo a edifícios de consumos energéticos quase nulos (Nearly zero energy building - NZEB). Aliás, na última década, foram vários os conceitos formulados sobre edifícios de elevado desempenho energético, desde "low-energy building", "passive building", "zeroenergy building", "positive energy building" e até mesmo "autonomous building" (THIERS; PEUPORTIER, 2012). Para o Programa de Tecnologias de Edifícios do Departamento de Energia dos EUA, o objetivo estratégico passa por alcançar "[...] marketable zero energy homes in 2020 and commercial zero energy buildings in 2025 [...]" (SARTORI; NAPOLITANO; VOSS, 2012, p. 220). Infelizmente, o problema das definições de âmbito comercial é o de não garantirem à partida a necessária e desejável eficiência energética, pois é sempre possível reduzir o consumo energético comercial pela utilização de fontes de energia renovável não otimizadas, como, por exemplo, o uso de painéis solares ou fotovoltaicos com áreas sobredimensionadas, ao invés de começar-se por reduzir os desperdícios energéticos nas habitações (SARTORI; NAPOLITANO; VOSS, 2012). Os conceitos e definições sobre edifícios de consumos energéticos quase nulos ou mesmo nulos são ainda hoje matéria objeto de discussão em âmbito internacional (DALL'O'; BRUNI; SARTO, 2013). Alguns autores utilizam ZEB para "net zero energy buildings" e NZEB para "nearly zero-energy buildings" (Figura 3). 
Figura 3 - Edifício Solar XXI, construído entre 2004 e 2005 (inaugurado em 2006) no campus do Ineti em Lisboa, com base no conceito "Towards net zero energy"

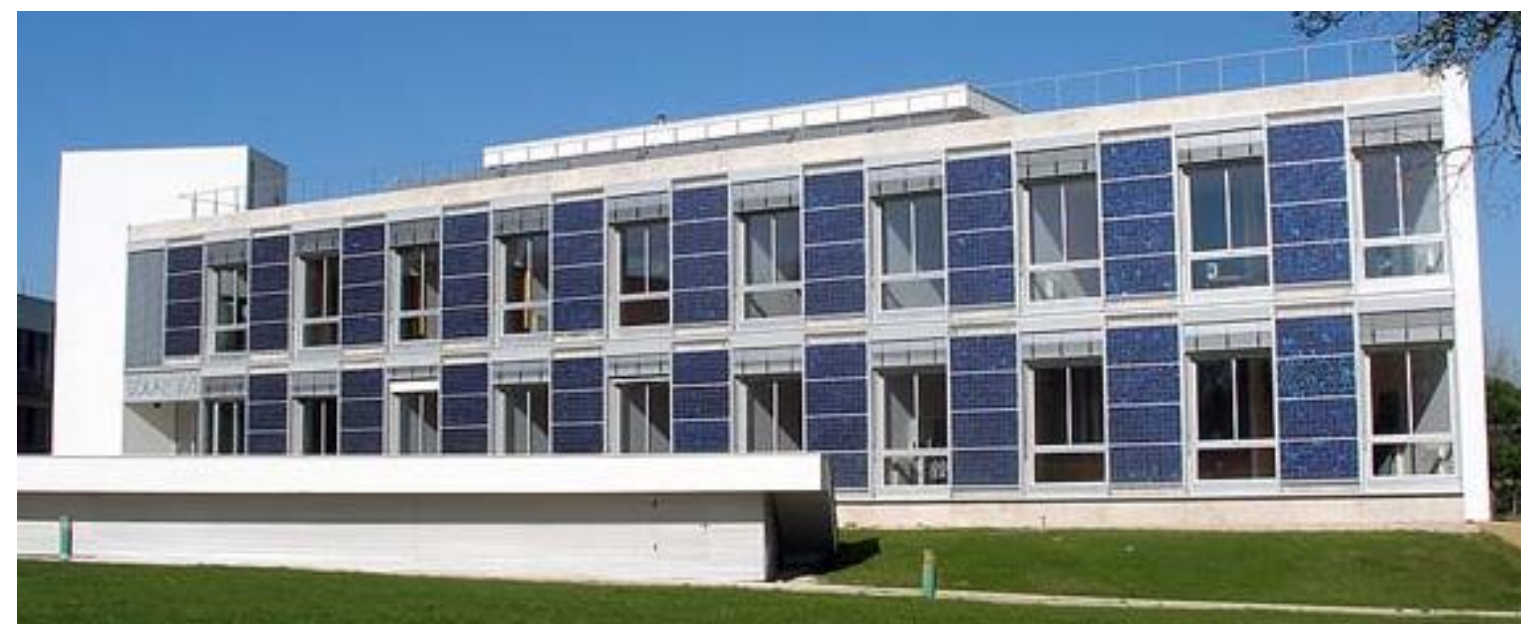

O termo "net" refere-se ao saldo energético entre a energia fornecida e a energia devolvida à rede durante certo período, usualmente um ano, o que significa que "Net ZEB" refere-se a edifícios com saldo zero, enquanto o conceito incluso na nova EPBD refere-se a edifícios com saldo energético negativo. Das várias novidades inclusas na nova EPBD, o conceito NZEB é aquele de mais difícil transposição por parte dos Estados-membros. O artigo 9 aponta para 31 de dezembro de 2020 como a data-limite a partir da qual todos os novos edifícios deverão respeitar o conceito NZEB (31 de dezembro de 2018 para os edifícios públicos). $\mathrm{O}$ artigo 2 da nova EPBD explicita esse conceito da seguinte forma (EUROPEAN..., 2010b, p. 6):

Edifício com necessidades quase nulas de energia é um edifício com um desempenho energético muito elevado, determinado nos termos do anexo I. As necessidades de energia quase nulas ou muito pequenas deverão ser cobertas em grande medida por energia proveniente de fontes renováveis, incluindo energia proveniente de fontes renováveis produzida no local ou nas proximidades.

Como nas versões iniciais da nova Diretiva faziase referência ao conceito "Net zero" em vez de "Nearly zero", que foi aquele que passou a constar da versão aprovada da nova EPBD, alguns autores acreditam que essa mudança ficou a dever à atual crise econômica e ao fato de os decisores políticos terem preferido optar por uma meta menos ambiciosa, mas também que requer menores investimentos (ADHIKARI et al., 2012). Aos Estados-membros foi dado um prazo para a transposição e adaptação da nova EPBD para o direito jurídico interno, levando em linha de conta as diferentes especificidades de cada país (condições climáticas, aspectos econômicos, práticas construtivas, etc.). Contudo, somente a Dinamarca, a Irlanda e a Suécia o conseguiram fazer em tempo, razão pela qual em 21 de setembro de 2012 foram instaurados processos de infração contra os 24 países que não procederam a essa transposição dentro do prazo. Outro conceito que pode ter contribuído para dificultar o processo de transposição prende-se com o nível de rentabilidade ótimo. $\mathrm{O}$ artigo 4 refere que:

Os Estados-Membros tomam as medidas necessárias para assegurar que sejam estabelecidos requisitos mínimos de desempenho energético dos edifícios ou das fracções autónomas a fim de alcançar níveis óptimos de rentabilidade. (EUROPEAN..., 2010b, p. 7).

Já o artigo 5 refere que os níveis de rendibilidade ótimos são calculados de acordo com uma metodologia comparativa estabelecida pela Comissão Europeia, cabendo a cada Estadomembro calcular "[...] os níveis óptimos de rentabilidade dos requisitos mínimos de desempenho energético utilizando o quadro para a metodologia comparativa [...] e parâmetros relevantes, como as condições climáticas e a acessibilidade prática da infra-estrutura energética [...]" (EUROPEAN..., 2010b, p. 7). O problema, neste caso, prende-se com o fato de as emissões de gases com efeito estufa e o consequente aquecimento global poderem implicar que os requisitos mínimos de desempenho atuais possam ser muito diferentes daqueles que venham a ser necessários nas próximas décadas. Crawley (2008, p. 91) refere que 
[...] o impacto das alterações climáticas pode vir a resultar numa redução do consumo de energia de aprox. $10 \%$ em edifícios localizados em climas frios, num aumento da redução do consumo de energia de aprox. $20 \%$ em edifícios localizados nos trópicos e numa mudança de necessidades de aquecimento para necessidades de arrefecimento em edificios localizados em zonas de climas moderados.

Outros autores, como Roetzel e Tsangrassoulis (2012), referem que, dependendo da zona climática, as necessidades de arrefecimento em edifícios poderão vir a aumentar entre $50 \%$ e $90 \%$. Alguns autores (KWOK; RAJKOVICH, 2010) sugerem, por isso, que os regulamentos sobre parâmetros de conforto e de consumo energético em edifícios devem incorporar não só medidas de mitigação de gases responsáveis por efeito de estufa como também medidas de adaptação às alterações climáticas. Recentemente, Ren, Chen e Wang (2011) analisaram várias medidas de adaptação de edifícios às alterações climáticas, incluindo sua eficiência econômica.

Uma das limitações da nova EPBD tem a ver com o fato de as metas relativas ao conceito NZEB não serem válidas para os edifícios existentes, havendo somente a recomendação de cada país ter que ir reabilitando gradualmente o número de edifícios existentes, transformando-os em NZEB. Esse fato, embora possa ser entendível no contexto de que se já é difícil aplicar o conceito NZEB aos edifícios novos, a partir de 2020 (2018 para edifícios públicos), muito mais difícil o seria no caso dos edifícios existentes. Tal circunstância é, no entanto, difícil de articular com as metas ambiciosas da UE em termos de eficiência energética, já referidas no presente artigo. Até porque as necessidade energéticas dos novos edifícios a construir a partir de 2020 (ou 2018) constituirão apenas uma pequena fração comparativamente às elevadas necessidades energéticas dos edifícios já existentes, que, na sua maioria, caracterizam-se por um elevado nível de desperdício energético (XING; HEWITT; GRIFFITHS, 2011). Além disso, importa ter presente que a execução de novos edifícios implica um consumo de matérias-primas que é de $400 \%$ a $800 \%$ superior às necessárias para obras de reabilitação (POWER, 2008), fato que constitui um argumento extra em favor desta última. Percebe-se, assim, por que motivo a UE aprovou em 25 de outubro de 2012, no âmbito de uma Diretiva para a Eficiência Energética (EUROPEAN..., 2012), medidas para os edifícios públicos existentes. Segundo esta, os Estadosmembros terão até 5 de junho de 2014 para proceder à respectiva transposição para a ordem jurídica interna. $\mathrm{O}$ artigo 4 da Diretiva refere que os mesmos terão que definir (EUROPEAN..., 2010b, p. 7):

[...] uma estratégia a longo prazo para mobilizar investimentos na renovação do parque nacional de edifícios residenciais $e$ comerciais, tanto públicos como privados. Essa estratégia compreende:

a) uma panorâmica do parque imobiliário nacional baseada, se adequado, numa amostragem estatística;

b) uma identificação das abordagens rentáveis das renovações relevantes para o tipo de edifício e para a zona climática;

c) políticas e medidas destinadas a incentivar renovações profundas de edifícios rentáveis, incluindo renovações profundas por etapas;

d) uma perspetiva de futuro destinada a orientar a tomada de decisões em matéria de investimento por particulares, pela indústria da construção e pelas instituições financeiras;

e) uma estimativa, com base em dados factuais, das economias de energia esperadas e de outros benefícios possíveis.

Já o artigo 5 estabelece que (EUROPEAN..., 2010a, p. 8):

[...] cada Estado-Membro assegura que, a partir de 1 de janeiro de 2014, sejam renovados todos os anos $3 \%$ da área construída total dos edifícios aquecidos elou arrefecidos detidos e ocupados pelas respetivas administrações centrais, a fim de cumprir pelo menos os requisitos mínimos de desempenho energético por si estabelecidos em aplicação do artigo $4 \mathrm{da}$ Diretiva 2010/31/EU. Essa taxa de 3\% é calculada sobre a área construída total dos edifícios com uma área útil total superior a $500 \mathrm{~m}^{2}$ detidos e ocupados pela administração central do Estado-Membro em causa e que, em 1 de janeiro de cada ano, não cumpram os requisitos mínimos nacionais de desempenho energético fixados em aplicação do artigo 4 da Diretiva 2010/31/UE. A partir de 9 de julho de 2015, esse limiar é reduzido para 250 $m^{2}$.

Contudo, como o horizonte temporal é bastante extenso (até 2050), isso significa que a UE optou por colocar o foco da eficiência energética nos edifícios novos, atuando nos edifícios existentes de 
forma muito pouco incisiva, o que pode ter como consequência que os ganhos energéticos e ambientais associados a uma tal estratégia sejam bastante menores do que se o foco fosse direcionado para os edifícios existentes, onde os desperdícios energéticos são bastante maiores.

\section{Energia incorporada: uma estranha omissão}

Por definição, a energia incorporada nos materiais de construção (embodied energy) abrange a energia consumida durante sua vida útil (HAMMOND; JONES, 2008). Existem, no entanto, diferentes abordagens para a referida definição, a saber: do início da extração das matérias-primas até a porta da fábrica (cradle to gate); do início até a obra (cradle to site), ou do início até a fase de demolição e da deposição (cradle to grave). Berge (2009) considera como energia incorporada somente a energia necessária para colocar o material ou produto à porta da fábrica (o primeiro caso), sendo que a energia de transporte e de aplicação incluem-se na fase de construção do edifício. Segundo esse autor, a energia incorporada num material representa, assim, entre $85 \%$ e $95 \%$ de sua energia total. Já os restantes $5 \%$ a $15 \%$ respeitam aos processos de construção, manutenção e demolição do edifício. No segundo caso, do berço à obra, a energia incorporada nos materiais de construção engloba a energia utilizada na extração das matérias-primas, na fase de produção, no transporte e na aplicação dos materiais em obra. Neste caso, a demolição e a eventual reciclagem dos mesmos incluem-se numa fase específica da análise de ciclo de vida do edifício. No terceiro caso, a energia incorporada abrange todos os consumos, desde a fase de produção até o fim de vida do material ou produto.
Relativamente à parcela da energia de transporte, esta varia consoante o modo de transporte utilizado: marítimo, aéreo, rodoviário ou ferroviário. Nas últimas décadas considerou-se que a energia operacional dos edifícios (iluminação, aquecimento, arrefecimento, etc.) representava a parte preponderante dos consumos energéticos, aceitando-se que a energia incorporada não fosse muito além de $10 \%$. Consequentemente, a maioria dos esforços, quer institucionais, quer ao nível da investigação, foram no sentido de tentar reduzir a primeira. Contudo, à medida que isso se vai sucedendo, em virtude de haver edifícios cada vez mais eficientes em termos energéticos, maior peso adquire a parcela da energia incorporada. Thormark (2002) estudou um dos edifícios com o menor consumo energético na Suécia $\left(45 \mathrm{kWh} / \mathrm{m}^{2}\right)$ e referiu que a energia incorporada nos materiais, para uma vida útil de 50 anos, pode representar $45 \%$ da energia total. Convém ter presente que esse autor não contabilizou a energia gasta durante a fase de construção, mas contabilizou a parcela de energia para substituição de materiais durante a fase de manutenção. Dimoudi e Tompa (2008) referem que a energia incorporada nos materiais de construção, em edifícios de escritórios, pode variar entre $13 \%$ e $19 \%$ da energia operacional, para uma vida útil do edifício de 50 anos. Estes autores contabilizam somente a parcela de energia referente à produção de materiais. Pacheco-Torgal, Faria e Jalali (2013) analisaram a energia operacional e a energia incorporada de um edifício localizado na região do Grande Porto, constituído por 97 apartamentos com uma área bruta de 27.647 $\mathrm{m}^{2}$. Estes autores comprovaram que o concreto armado (concreto simples e armaduras de aço) é responsável por mais de $70 \%$ da energia incorporada nos materiais (Figura 4).

Figura 4 - Energia incorporada nos materiais responsáveis pela parcela mais significativa do consumo

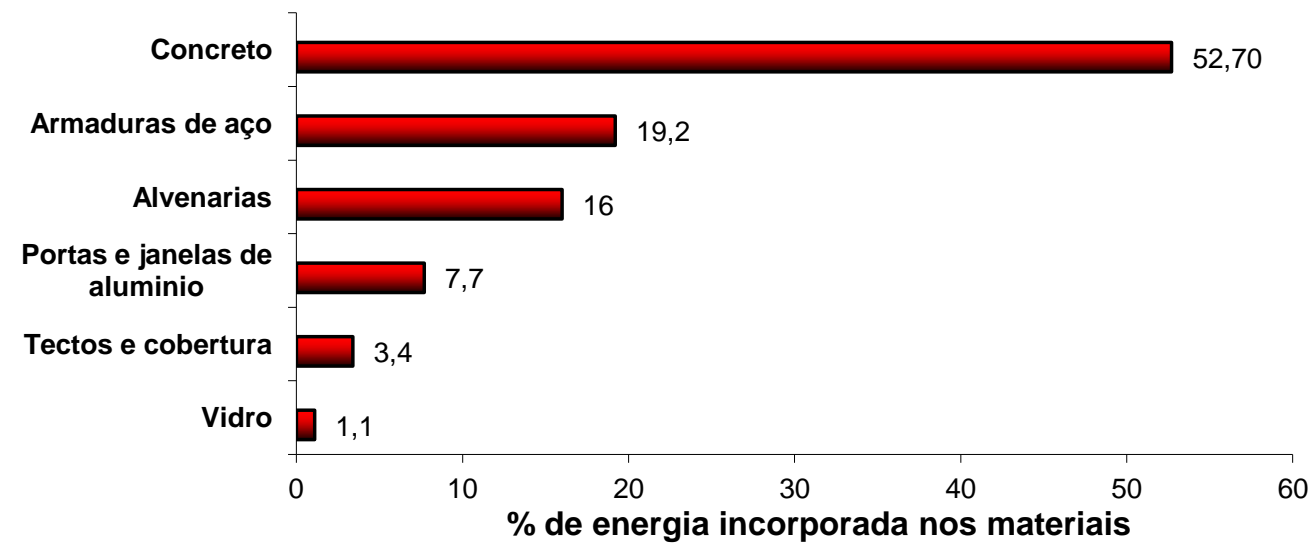


Para a energia utilizada durante a construção do edifício, foi utilizado o valor de $10 \%$ da energia de produção dos materiais acima referidos, o que dá um valor de 5.824.933 MJ. Da soma das três parcelas obtêm-se o valor de 65.589.464 MJ, o que corresponde a uma valor unitário de $2.372 \mathrm{MJ} / \mathrm{m}^{2}$. Esse valor representa $25,3 \%$ da energia operacional para um período de 50 anos. Caso esse edifício fosse construído novamente, para ter um desempenho energético muito eficiente (classe energética $\mathrm{A} \mathrm{A}+$ ), ele necessitaria apenas de um valor de energia operacional de $12 \mathrm{MJ} / \mathrm{m}^{2} /$ ano. Isso significaria apenas $600 \mathrm{MJ} / \mathrm{m}^{2}$ para os 50 anos de vida útil da habitação do presente caso de estudo. Logo, para uma vida útil de 50 anos, a energia incorporada nos materiais representaria $400 \%$ do valor da energia operacional. Como o conceito "edifícios de consumo energético quase nulo" da nova Diretiva irá reduzir ainda mais os consumos de energia operacional, isso significa que a energia incorporada nos materiais será, no futuro, ainda mais preponderante. A incorporação de requisitos de energia incorporada na Diretiva EPBD agora aprovada tinha já sido sugerida por Szalay (2007). Sem sucesso, porém. Em vez disso, a estratégia da UE foi a de abordar o desempenho ambiental dos materiais de construção no novo regulamento de produtos de construção (PACHECO-TORGAL, 2012). Em 9 de março de 2011, o Parlamento e o Conselho Europeu aprovaram o novo Regulamento de Produtos da Construção 305/2011 (RPC) (EUROPEAN..., 2011), o qual, a partir de $1^{\circ}$ de julho de 2013, irá substituir de forma integral a Diretiva dos Produtos da Construção 89/106/CEE (DPC) (EUROPEAN..., 1989). Esta, por sua vez, já tinha sido anteriormente alterada pela Diretiva 1993/68/EEC (EUROPEAN..., 1993). Quando se comparam os requisitos básicos do RPC e as antigas exigências da DPC, constata-se que ao novo Regulamento foi adicionado um novo requisito, relacionado com a utilização sustentável dos recursos naturais. Isso significa que a produção e comercialização de futuros produtos de construção se fará num contexto de maior respeito ambiental. Essa opção, embora possa, à partida, fazer algum sentido, pode, por outro lado, não constituir garantia suficiente para que a indústria da construção opte por materiais de desempenho ambiental melhorado caso tenham um preço superior.

\section{Conclusões}

No espaço europeu os edifícios são responsáveis por uma parte substancial das emissões de gases responsáveis pelo efeito estufa, razão pela qual a UE aprovou regulamentação ambiciosa com vista ao aumento da eficiência energética dele. Contudo, alguns conceitos da nova Diretiva EPBD padecem de certa ambiguidade e dificultam sua transposição para o direito interno de cada Estado-membro, resultando na instauração de um procedimento de infração contra 24 deles. Para agravar o problema, a inércia dos sistemas atmosféricos (o elevado tempo de retorno à situação inicial) torna necessário que qualquer regulamentação sobre a eficiência energética dos edifícios deva incluir não só medidas que permitam mitigar as consequências das alterações climáticas como também de adaptação às alterações que venham a ocorrer no curto e no médio prazo, embora o conceito de "edifícios de consumo energético quase nulo" incluso na nova Diretiva seja válido somente para os edifícios novos a construir a partir de 31 de dezembro de 2020 (31 de dezembro de 2018 para os edifícios públicos), um objetivo que a realidade mostra não ser fácil atingir. É necessário reconhecer que as poupanças energéticas a obter por essa via serão muito menores do que se o foco da Diretiva EPBD tivesse sido direcionado para os edifícios já existentes, onde os desperdícios energéticos são mais elevados e onde, por essa via, se poderiam obter maiores poupanças energéticas. $O$ fato de a Diretiva EPBD ser omissa no que respeita a requisitos relativos à energia incorporada nos materiais de construção afigura-se como um fato desencorajador da utilização de materiais com uma menor "pegada energética".

\section{Referências}

ADHIKARI, R. et al. Net Zero Energy Buildings: expense or investment? Energy Procedia, v. 14, p. 1331-1336, 2012.

ANTHONY, K. et al. Ocean Acidification Causes Bleaching and Productivity Loss in Coral Reef Builders. Proceedings of the National Academy of Sciences of the United States of America, v. 105, n. 45, p. 17442-17446, 2008.

BERGE, B. The Ecology of Building Materials. 2. ed. Oxford: Architectural Press, Elsevier Science, 2009.

BOURNE, J. Temperature Has Already changed. National Geographic Magazine, Washington, v. 77, p. 823-850, 2008.

CLEMENTS-CROOME, D. Sustainable Intelligent Buildings For Ppeople: a review. Intelligent Buildings International, v. 3, n. 2, p. 67-86, 2011.

COSTANZA, R. et al. The Value of the World's Ecosystem services and Natural Capital. Nature, v. 387, p. 253-260, 15 may 1997. 
CRAWLEY, D. Estimating the Impacts of Climate Change and Urbanization on Building Performance. Journal of Building Performance Simulation, v. 1, n. 2, p. 91-115. 2008,

DALL'O', G.; BRUNI, E.; SARTO, L. An Italian Pilot Project For Zero Energy Buildings: towards a quality-driven approach. Renewable Energy, v. 50, p. 840-846, 2013.

DIMOUDI, A.; TOMPA, C. Energy and Environmental Indicators Related to Construction of Office Buildings. Resources Conservation and Recycling, v. 53, n. 1/2, p. 86-95, dec. 2008.

DIMITROV, R. Inside UN Climate Change Negotiations: the Copenhagen conference. Review of Policy Research, v. 27, n. 6, p. 795-821, 2010.

EUROPEAN COMMISSION. COM 808 final: horizon 2020: the framework programme for research and innovation. Brussels, 2011b. Disponível em: <http://eurlex.europa.eu/LexUriServ/LexUriServ.do?uri=CO M:2011:0808:FIN:en:PDF>. Acesso em: 05 dez. 2013.

EUROPEAN COMMISSION. COM 885/2: energy roadmap 2050. Brussels, 2011a. Disponível em:

<http://ec.europa.eu/energy/energy2020/roadmap/ doc/com_2011_8852_en.pdf >. Acesso em: 05 dez. 2013.

EUROPEAN COMMISSION. COM 571 Final: roadmap to a resource efficient europe. Brussels, 2011a. Disponível em:

$<$ http://ec.europa.eu/environment/resource_efficie ncy/pdf/com2011_571.pdf >. Acesso em: 05 dez. 2013.

\section{EUROPEAN COMMISSION. COM 639 Final:}

energia 2020: estratégia para uma energia competitiva, sustentável e seguraBruxelas, 2010a. Disponível em: <http://eur-

lex.europa.eu/LexUriServ/LexUriServ.do?uri=CO M:2010:0639:FIN:PT:PDF>. Acesso em: 05 dez. 2013.

EUROPEAN COMMISSION. COM 30: 2020 by 2020: europe's climate change opportunity. Brussels, 2008. Disponível em: <http://eurlex.europa.eu/LexUriServ/LexUriServ.do?uri=CO M:2008:0030:FIN:en:PDF>. Acesso em: 05 dez. 2013.

EUROPEAN UNION. Directive 93/68/EEC, of 22th July, 1993. Official Journal of the European Communities, 30 August 1993.

EUROPEAN UNION. Directive 2012/27/EU, of 25 October 2012. Official Journal of the European Union, 14 November 2012.
EUROPEAN UNION. Directive 2002/91/EC, of $16^{\text {th }}$ December 2002. Official Journal of the European Communities, 4 January 2003.

EUROPEAN UNION. Directive 2010/31/EU, of $19^{\text {th }}$ May 2010. Official Journal of the European Union, 18 June 2010b.

EUROPEAN UNION. Directive 89/106/EEC, of $21^{\text {th }}$ December, 1988. Official Journal of the European Communities, 11 February 1989.

EUROPEAN UNION. Regulation (EU) 305/2011, of $9^{\text {th }}$ March 2011. Official Journal of the European Communities, 4 April 2011.

GOLDENBERG, J.; PRADO, L. The "Decarbonization" of the World's Energy Matrix. Energy, v. 38, p. 3274-3276, 2010.

HAMMOND, G.; JONES, C. Inventory of Carbon and Energy (ICE). Version 1,6a. 2008.

HARROULD-KOLIEB, E.; HERR, D. Ocean Acidification and Climate Change: synergies and challenges of addressing both under the UNFCCC. Climate Policy, v. 12, n. 3, p. 378-389, 2012.

HOFMANN, M.; SCHELLNHUBER, H. Ocean Acidification: a millennial challenge. Energy and Environmental Science, v. 3, n. 12, p. 1883-1896, 2010.

INTERGOVERNMENTAL PANEL ON

CLIMATE CHANGE. Climate Change: synthesis report. Geneva: IPCC, 2007.

INTERNATIONAL ENERGY AGENCY. World Energy Outlook 2012. Paris: OECD/IEA, 2012.

JOINT RESEARCH CENTRE. Trends in Global $\mathrm{CO}_{2}$ Emissions. Report 2012. Disponível em: $<$ http://edgar.jrc.ec.europa.eu/CO2REPORT2012.p df>. Acesso em: 05 dez. 2013.

KWOK, A. RAJKOVICH, N. Addressing Climate Change in Comfort Standards. Building and Environment, v. 45, n. 1, p. 18-22, 2010.

LECHTENBOHMER, S. SCHURING, A. The Potential For Large-Scale savings From Insulating Residential Buildings in the EU. Energy

Efficiency, v. 4, n. 2, p. 257-270, 2011.

LUND, H.; HVELPLUND, F. The Economic Crisis and Sustainable development: the design of job creation strategies by use of concrete institutional economics. Energy, v. 43, p. 192-200, 2012.

NEW, M. et al. Four Degrees and Beyond: the potential for a global temperature increase of four degrees and its implications. Philosophical Transactions of the Royal Society A:

Mathematical, Physical and Engineering Sciences, v. 369, p. 9-19, 2011. 
PACHECO-TORGAL, F.; JALALI, S. EcoEfficient Construction and Building Materials. London: Springer Verlag, 2011.

PACHECO-TORGAL, F. O Novo Regulamento de Produtos de Construção: incentivando a utilização de produtos eco-eficientes. Revista Maquinaria, v. 221, p. 54-57, 2012.

PACHECO-TORGAL, F.; FARIA, J.; JALALI, S. Embodied Energy Versus Operational Energy: showing the shortcomings of the energy performance building directive (EPBD). Materials Science Forum, v. 730-732, p. 587-591, 2013.

PETERSON, E.; SCHLEICH, J.; DUSCHA, V. Environmental and Economic Effects of the Copenhagen Pledges and More Ambitious Emission Reduction Targets. Energy Policy, v. 39, p. 3697-3708, 2011.

PIKE Research. Energy efficient buildings: Global Outlook, 2011.

REN, Z.; CHEN, Z.; WANG, X. Climate Change adaptation Pathways for Australian Residential Buildings. Building and Environment, v. 46, n. 11, p. 2398-2412, 2011.

ROETZEL, A.; TSANGRASSOULIS, A. Impact of Climate Change on Comfort and Energy Performance in Offices. Building and

Environment, v. 57, p. 349-361, 2012.

RYAN, L.; SELMET, N.; AASRUD, A. Plugging the Energy Efficiency Gap with Climate Finance. Paris: OECD/IEA, 2012.

SARTORI, I.; NAPOLITANO, A.; VOSS, K. Net Zero Energy Buildings: a consistent definition framework. Energy and Buildings, v.48, p.220232, 2012.
SHEALY, M.; DORIAN, J. Growing Chinese Coal Use: dramatic resource and environmental implications. Energy Policy, v. 38, p. 2116-2122, 2009.

STERN, N.; TREASURY, G. The Economics of Climate Change: the Stern review. Cambridge: Cambridge University Press, 2007.

SZALAY, A. What Is Missing From the Concept of the New European Building Directive. Building and Environment, v. 42, n. 4, p. 1761-1769, 2007.

THIERS, S.; PEUPORTIER, B. Energy and Environmental assessment of Two High Energy Performance Residential Buildings. Building and Environment, v. 51, p. 276-284, 2012.

THORMARK, C. A Low Energy Building in a Life Cycle: its embodied energy, energy need for operation and recycling potential. Building and Environment, v. 37, p. 429-435, 2002.

UNITED NATIONS. Copenhagen Accord. 2009. Disponível em:

<http://unfecc.int/resource/docs/2009/cop15/eng/10 7.pdf>. Acesso em: 05 dez. 2013.

VALERO, A.; AGUDELO, A. VALERO, A. The Crepuscular Planet: a model for the exhausted atmosphere and hydrosphere. Energy, v. 36, n. 6, p. 3745-3753, 2011.

VIJAYAVENKATARAMAN, S.; INIYAN, S.; GOIC, R. A Review of Climate Change, Mitigation and Adaptation. Renewable and Sustainable Energy Reviews, v. 16, n. 1, p. 878897, 2012.

XING, Y.; HEWITT, N.; GRIFFITHS, P. Zero Carbon Buildings Refurbishment: a hierarchical pathway. Renewable and Sustainable Energy Reviews, v. 15, n. 6, p. 3229-3236, 2011.

\section{Revista Ambiente Construído}

Associação Nacional de Tecnologia do Ambiente Construído

Av. Osvaldo Aranha, $99-3^{\circ}$ andar, Centro

Porto Alegre - RS - Brasil CEP $90035-190$

Telefone: +55 (51) 3308-4084

Fax: +55 (51) 3308-4054

www.seer.ufrgs.br/ambienteconstruido

E-mail: ambienteconstruido@ufrgs.br 